(c) Elsevier/Inra

Original article

\title{
Genetic analysis by interspecific crosses of the tolerance of Drosophila sechellia to major aliphatic acids of its host plant
}

\author{
M Amlou, E Pla, B Moreteau, JR David \\ Laboratoire populations, génétique et évolution, \\ Centre national de la recherche scientifique, 91198 Gif-sur-Yvette cedex, France
}

(Received 3 March 1997; accepted 11 July 1997)

\begin{abstract}
Summary - Toxicity of hexanoic and octanoic acid, ie, the two major aliphatic acids found in ripe fruits of Morinda citrifolia, was measured on adult flies of Drosophila sechellia, $D$ simulans, $\mathrm{F} 1$ hybrids and backcrosses. With both acids, tolerance was much higher in $D$ sechellia than in $D$ simulans while $\mathrm{F} 1$ and backcross progeny exhibited intermediate characteristics. Tolerance to these two acids in $D$ sechellia appears to be a major mechanism for understanding the ecological specialization of that species to the toxic morinda. Significant differences in tolerance were found between sexes, especially in F1 hybrids. The role of X-linked tolerance genes was, however, not obvious from the backcross generation, and most of the interspecific difference seems to be autosomal and polygenic. Attempts were made to introgress the tolerance of $D$ sechellia into $D$ simulans by selecting with either morinda fruit or pure octanoic acid. Both techniques proved to be unsuccessful. Introgressed genotypes progressively returned to the apparently pure $D$ simulans phenotype and tolerance regressed to the low value typical of that species. This barrier against introgression seems quite similar to the barrier observed in hybrid zones of various animal species.
\end{abstract}

ecological specialization / hexanoic acid / octanoic acid / interspecific hybrids / barrier to introgression

Résumé - Analyse génétique par croisement interspécifique de la tolérance de Drosophila sechellia aux deux principaux acides aliphatiques de sa plante hôte. La toxicité de l'acide hexanoïque et de l'acide octanoïque, deux acides aliphatiques majoritaires dans le fruit mûr de Morinda citrifolia, a été mesurée chez les adultes de D sechellia, de $\mathrm{D}$ simulans, les hybrides $F 1$ et les individus issus de rétrocroisements avec les deux parents. Pour les deux acides, D sechellia est beaucoup plus tolérante que D simulans. Les $F 1$ et les rétrocroisements montrent des caractéristiques intermédiaires. La tolérance de $\mathrm{D}$ sechellia à ces deux acides semble être le mécanisme majeur permettant de comprendre la spécialisation écologique de cette espèce sur le morinda. Une différence significative de tolérance a été observée entre les mâles et les femelles, spécialement chez les F1. Le rôle du chromosome $X$, dans la tolérance à ces deux acides, n'est cependant pas clairement démontré et la majeure partie des différences interspécifiques semble être d'origine autosomale et polygénique. Des tentatives pour introgresser la tolérance de $\mathrm{D}$ sechellia 
chez $\mathrm{D}$ simulans par sélection ont été entreprises, soit avec le fruit du morinda soit avec l'acide octanoïque. Les deux techniques se sont soldées par un échec total. Les génotypes introgressés retournent progressivement à un phénotype pur $\mathrm{D}$ simulans et leurs tolérances régressent également vers des faibles valeurs de DL50, caractéristiques de $\mathrm{D}$ simulans. Cette barrière contre l'introgression paraît similaire aux barrières rencontrées dans les zones d'hybridations chez différentes espèces animales.

spécialisation écologique / acide hexanoïque / acide octanoïque / hybrides interspécifiques / barrière à l'introgression

\section{INTRODUCTION}

The diversification of ecological niches by reduction of niche breadth is often considered as a consequence of interspecific competition and as a major cause for maintaining biodiversity in an ecosystem (Hutchinson, 1978; Tilman, 1982), although there are exceptions to this general rule (Connell, 1980). A long evolutionary time seems, however, to be needed for increasing the complexity of food webs and the number of coexisting species. The relative stability of tropical ecosystems, as compared to temperate ones, may explain why more numerous species are generally found in the tropics than in temperate biota (Pianka, 1974; Pielou, 1975); the Drosophilidae family follows this rule. For example, more than 400 species are known from the Afrotropical region (Tsacas et al, 1981), while only 80 species are found in Europe (Bächli and Rocha-Pité, 1981).

In insects, numerous cases of ecological specialization are known, especially among phytophagous species (Price, 1984; Harborne, 1989). Most investigated cases, however, are restricted to species comparisons, without any possibility of genetic analysis. There are only a few biological situations amenable to genetic investigation, including Papillio species (Thompson et al, 1990), the fly Rhagoletis (Feder et al, 1990a, b) and Drosophila sechellia (R'Kha et al, 1991).

$D$ sechellia, endemic to the Seychelles archipelago, is strictly specialized on a single resource, the fruit of Morinda citrifolia (Tsacas and Bächli, 1981; Lachaise et al, 1986; Louis and David, 1986), although it can be reared on usual laboratory food. Using its natural resource, frozen morinda, it was shown that, compared to its sibling $D$ simulans, $D$ sechellia is tolerant to fruit toxicity, that adults are not repelled but attracted by the resource, that females prefer to oviposit on morinda, and that morinda stimulates, instead of inhibits, oogenesis (R'Kha et al, 1991, 1997; Legal et al, 1992).

For the analysis of such a specialization, a knowledge of the responsible specific chemicals is needed. More than 150 different compounds were identified from the ripe morinda fruit (Farine et al, 1996) among which two aliphatic acids, hexanoic and octanoic acids, are present in large amounts (Legal et al, 1994) and are mainly responsible for the typical smell of this fruit. Preliminary observations suggested that octanoic acid was mainly responsible for the toxicity (Farine et al, 1996). Higa and Fuyama (1993) investigated only hexanoic acid and found that it acted specifically on behavioral traits. Data from different investigators are however sometimes difficult to compare since different techniques are used. In the present work we analyzed the toxicity of the acids with exactly the same technique as that used for natural morinda (R'Kha et al, 1991). 
Genetic comparisons were made by comparing parental species, $D$ sechellia and $D$ simulans, their F1 hybrids and backcross progeny. We also tried to introgress the high tolerance of $D$ sechellia into the sensitive $D$ simulans. Both acids were found to be highly toxic for $D$ simulans and appear to be responsible for the toxicity of the natural resource. Tolerances of the hybrids and backcrosses were intermediate, suggesting mainly additive effects. Results of introgression attempts were negative.

\section{MATERIALS AND METHODS}

\section{Species and hybrids}

Mass cultures of $D$ simulans and $D$ sechellia were established by mixing isofemale lines collected in the Seychelles in 1985. Interspecific hybrids were produced by crossing females of $D$ simulans with males of $D$ sechellia, since this cross is much easier than the reciprocal one (Lachaise et al, 1986; R'Kha et al, 1991). Hybrid males are sterile but females are fully fertile. F1 females were backcrossed to both parental species, producing second generation progeny, designated as backcross (BCsim and BCsech). All experiments were carried out at $25^{\circ} \mathrm{C}$.

\section{Acid toxicity}

This trait was measured on adult flies. Larvae were grown at low population density, on an axenic killed-yeast, high-nutrient medium (David and Clavel, 1965). The use of such a medium prevents crowding effects and produces numerous adults in good physiological condition. After emergence, adults were anesthetized with $\mathrm{CO}_{2}$, distributed into groups of 20 males or females, and kept on the same medium for 3 days. Groups were then transferred into air tight plastic vials containing $2 \mathrm{~mL}$ of a $3 \%$ sucrose water solution on absorbent paper. This technique is similar to that implemented for measuring alcohol toxicity (David et al, 1986). With hexanoic and octanoic acid we faced a practical difficulty since their solubility in water is very low. Solutions of different concentrations could not be conveniently prepared. After various attempts, it turned out that a better technique was to deposit a given amount of acid (in $\mu \mathrm{L}$ ) with a micropipette on the wet absorbent paper at the bottom of each vial. Different doses were used in a single experiment. For each dose, at least four vials, ie, two with 20 males and two with 20 females, were used. Dead adults were recorded after 2 days.

As usual in toxicity studies, a large and uncontrolled variability was observed. For example, in the same experiment it was not rare to find, for a given dose, a vial where all the 20 flies were dead after 2 days, while in a similar vial $80 \%$ of the flies were still alive. Such variations are too great to be due to random sampling, and may be explained by the difficulty in achieving an even distribution of the toxin in each vial. Significant variations were also observed when repetitions of the same toxicity test were made apparently under the same experimental conditions. Such variations seem to be a general observation in toxicity studies using Drosophila adults (Chakir et al, 1993). For statistical analyses and comparisons, two possible strategies were implemented. In the first procedure, we considered the number of dead flies in each experimental vial. For each concentration, the average number 
may be calculated and helps to characterize different genotypes. An increase in dead fly number is observed with increasing doses of acid, as illustrated in figure 1. Such data can be analyzed using Anova and demonstrate significant effects of genotypes, doses and interaction.

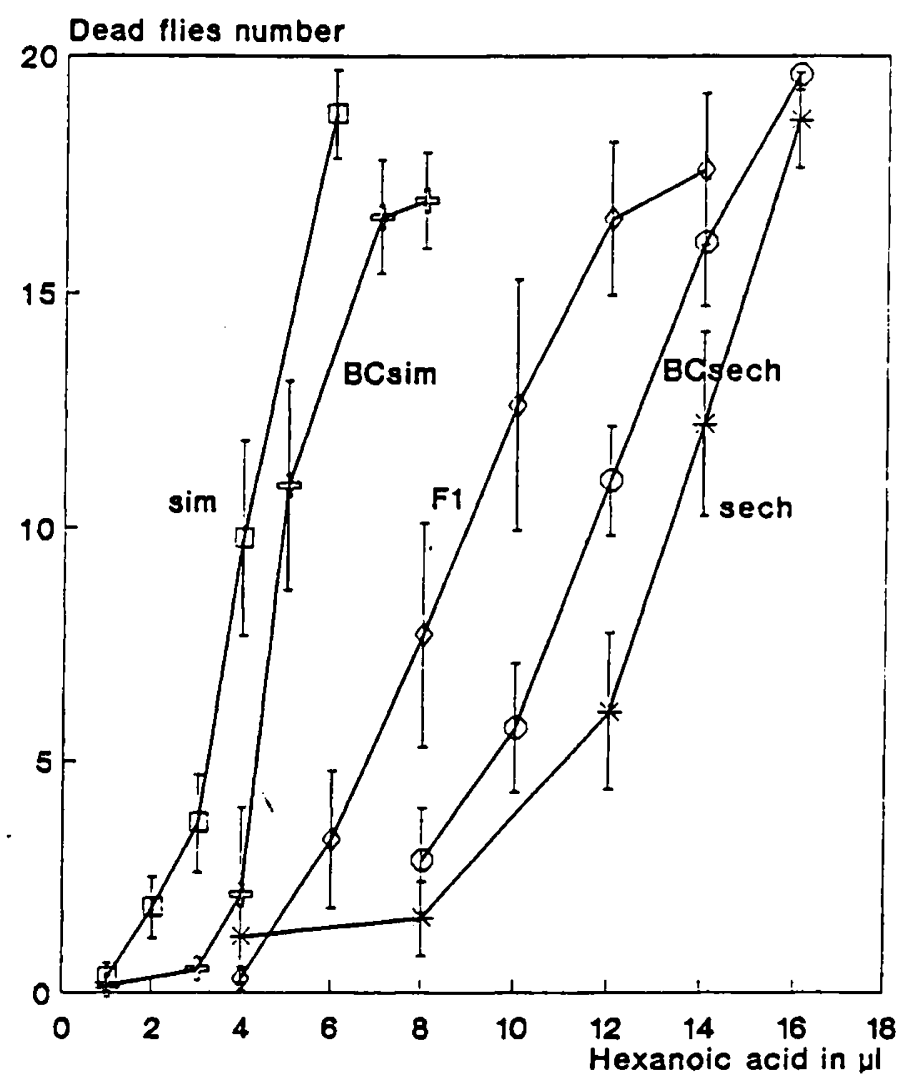

Fig 1. Mortality curves for $D$ sechellia, $D$ simulans and their hybrids according to increasing doses of hexanoic acid. Each point represents the mean number of dead flies, vertical bars indicate the confidence interval of the mean; 20 dead flies correspond to $100 \%$ mortality, sech: $D$ sechellia, BCsech: sechellia backcross, F1: hybrid, BCsim: simulans backcross, sim: $D$ simulans.

Another procedure, more usual in toxicity studies, was to estimate the toxicity by calculating the lethal dose, killing $50 \%$ of the flies (LD50) in a given time. For each experiment, from four up to six different doses were used. The LD50 was estimated, with a linear model, after log-probit data transformation, and the log LD50 was back transformed into microliters. For each genotype, at least five different experiments were realized. These values were averaged and a standard error calculated. 
These two procedures were used in all cases, and they led to basically identical conclusions. For the sake of simplicity, only data from the second procedure will be presented in the results section.

\section{Introgression experiments}

We tried to introgress the high tolerance of $D$ sechellia into $D$ simulans by submitting BCsim flies and further generations to selection, either with natural morinda or with octanoic acid. Such experiments were difficult because of the very low percentage of fertile males in the BCsim generation (Lachaise et al, 1986). With natural morinda, a huge mixed population was established in a population room at $25^{\circ} \mathrm{C}$, and observations were made after 4 months and about 8 generations. With octanoic acid, selection was applied on adult flies and surviving adults were used to produce the next generation. More details will be given in the results section.

\section{RESULTS}

\section{Comparison of acid toxicity in parent species, F1 and backcrosses}

To analyze and compare acid toxicity on the five genotypes, data of females and males were pooled and a single LD50 calculated in each experiment. For some genotypes, however, slight but significant differences were observed between sexes and this effect will be considered in the next section.

Average LD50 are illustrated in figure 2. D sechellia was highly tolerant to both acids with an LD50 of $13.06 \pm 0.10$ and $11.75 \pm 0.37 \mu \mathrm{L}$ for C6 and C8, respectively. $D$ simulans was found, on the other hand, to be very sensitive (LD50 of $4.20 \pm 0.09$ and $1.42 \pm 0.08 \mu \mathrm{L}$ for $\mathrm{C} 6$ and $\mathrm{C} 8)$. This major difference is similar to that found with natural morinda (R'Kha et al, 1991).

F1 hybrid flies exhibited a tolerance intermediate between the parents with an LD50 of $9.06 \pm 0.28$ and $6.45 \pm 0.26 \mu \mathrm{L}$ for $\mathrm{C} 6$ and $\mathrm{C} 8$, respectively. These values were not statistically different from the mid-parent $(8.63 \pm 0.07$ for $\mathrm{C} 6$ and $6.58 \pm 0.19 \mu \mathrm{L}$ for $\mathrm{C} 8$ ).

As expected, backcrosses towards parental species increased or decreased the LD50. With $D$ sechellia values of $11.63 \pm 0.20 \mu \mathrm{L}$ for $\mathrm{C} 6$ and $8.11 \pm 0.34 \mu \mathrm{L}$ for C8 were obtained. By contrast tolerance in the simulans backcross was much lower: $5.16 \pm 0.13 \mu \mathrm{L}$ for $\mathrm{C} 6$ and $3.37 \pm 0.22 \mu \mathrm{L}$ for $\mathrm{C} 8$.

For each acid, all differences between genotypes are significant. Also, a general tendency shows the $\mathrm{C} 8$ to be more toxic than the $\mathrm{C} 6$ under our experimental conditions, but the difference varies according to the genotype. In $D$ simulans the difference between acids is highly significant $(t=23.09, P<0.001)$ with a ratio (C6/C8) of LD50s equal to 2.97. In $D$ sechellia, the difference is still significant $(t=2.93, P=0.015)$ but the ratio is much less (1.11). Hybrid genotypes (F1 and backcrosses) exhibit intermediate ratios which are however more similar to $D$ sechellia than to $D$ simulans (1.39 in $\mathrm{BC}$ sech, 1.40 in $\mathrm{F} 1,1.53$ in $\mathrm{BC}$ sim). 

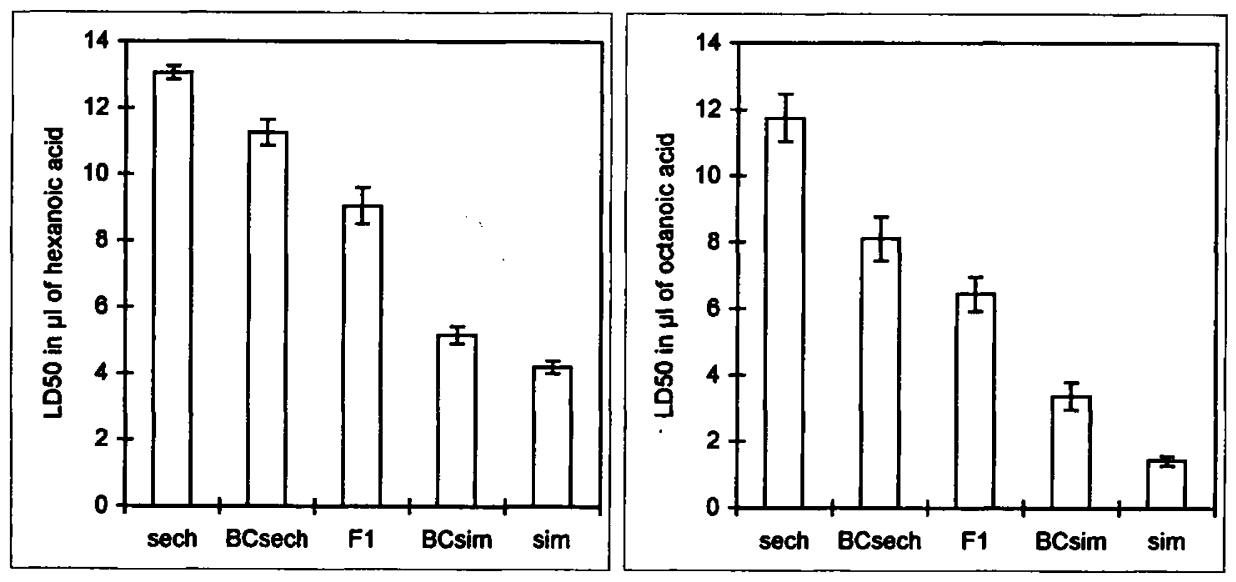

Fig 2. Mean LD50, lethal dose killing $50 \%$ of the flies (both sexes pooled) for the parent species, their F1 hybrid and two backcrosses, for hexanoic and octanoic acid. Vertical bars indicate the confidence interval of the mean. sech: $D$ sechellia, BCsech: sechellia backcross, F1: hybrid, BCsim: simulans backcross, sim: D simulans.

\section{Differences between sexes}

For each experiment, LD50s were calculated separately for males and females, and average data are presented in table I. In all cases, females proved to be more tolerant than males, and this major sex effect was evidenced by Anova (table II). For the two acids, a significant sex by genotype interaction was also observed. Looking at table I, we see that for C8, only a single difference, between F1 female and male, is significant. For the C6, on the other hand, significant differences are observed in the $D$ simulans parent, $\mathrm{F} 1$ and BCsech.

Table I. Values of LD50 ( $\mu \mathrm{L} \pm$ standard error) for hexanoic and octanoic acid according to sex and genotype.

\begin{tabular}{|c|c|c|c|c|c|c|c|c|}
\hline \multirow[t]{2}{*}{ Genotype } & \multicolumn{3}{|c|}{ Hexanoic acid } & \multicolumn{3}{|c|}{ Octanoic acid } & \multicolumn{2}{|c|}{ Sex difference } \\
\hline & $\mathrm{n}$ & Females & Males & $\mathrm{n}$ & Females & Males & C6 & $C 8$ \\
\hline & 5 & 13. & 12.64 & & $11.7 ?$ & 11.73 & $1.37^{\mathrm{NS}}$ & $0.06^{\mathrm{NS}}$ \\
\hline hellia & 5 & $11.74 \pm 0.67$ & $10.78 \pm 0.57$ & 8 & $8.80 \pm 1.80$ & $7.43 \pm 0.68$ & $2.43^{*}$ & $2.01^{\mathrm{NS}}$ \\
\hline F1 & 5 & $10.46 \pm 1.08$ & $7.65 \pm$ & 7 & $7.56 \pm 0.88$ & $5.34 \pm 1.10$ & $5.01^{* * *}$ & $4.17^{* *}$ \\
\hline BC simulans & 5 & $5.41 \pm 0.18$ & $4.90 \pm 0.56$ & 8 & $3.50 \pm 0.86$ & $3.24 \pm 0.87$ & $1.94^{\mathrm{NS}}$ & $0.62^{\mathrm{NS}}$ \\
\hline$D$ simulans & 7 & $4.70 \pm 0.39$ & $3.71 \pm 0.32$ & 8 & $1.52 \pm 0.37$ & $1.31 \pm 0.24$ & $5.21^{* * *}$ & $1.34^{\mathrm{NS}}$ \\
\hline
\end{tabular}

Differences between sexes for each acid are compared with Student's $t$-test. $n$ : number of repeats ie, successive independent experiments. NS: not significant, ${ }^{*} P<0.05$, ** $P<0.01,{ }^{* * *} P<0.001$. 
Table II. Results of Anova on data of table I.

\begin{tabular}{lccccccc}
\hline & \multicolumn{3}{c}{ Hexanoic acid } & & \multicolumn{3}{c}{ Octanoic acid } \\
\cline { 2 - 4 } \cline { 6 - 8 } Source of variation & $d f$ & $M S$ & $F$ & & $d f$ & $M S$ & $F$ \\
\hline Genotype & 4 & 165.92 & $365.07^{* * *}$ & & 4 & 245.87 & $224.52^{* * *}$ \\
Sex & 1 & 18.43 & $40.55^{* * *}$ & & 1 & 12.75 & $11.64^{* *}$ \\
Interaction & 4 & 2.18 & $4.79^{* *}$ & & 4 & 3.2 & $2.92^{*}$ \\
Error & 44 & 0.45 & & & 66 & 1.09 & \\
\hline
\end{tabular}

df: degrees of freedom, MS: mean square, $\mathrm{F}$ : variance ratio. Significance level: ${ }^{*} P<0.05$, ** $P<0.01,{ }^{* * *} P<0.001$.

\section{Introgression experiments}

A first experiment was carried out with natural morinda. Because of the behavioral attraction of $D$ sechellia adults to morinda and of the repulsion of $D$ simulans, we found it possible to have the two species coexisting on two different resources, banana and morinda, in the same population room at $25^{\circ} \mathrm{C}$. Resources were put in open jars, seeded with live yeast and set on two different tables, approximately $2 \mathrm{~m}$ apart. $D$ simulans colonized exclusively the banana while $D$ sechellia remained over the morinda. This coexistence lasted for more than 6 months and during that time, only two hybrid males were found among several hundreds examined. Finally it was decided to suppress banana while the $D$ simulans adults remained in the room. The only available resource was morinda seeded with live yeast. This proved to be insufficiently toxic to kill the $D$ simulans population so that their larvae developed on this rotten resource. Also, adults of the two species started to mate on the resource and to produce hybrid progeny. After 6 weeks (about three generations) most of the males could be classified as introgressed hybrids by examination of their genitalia. Progressively, the proportion of hybrid male phenotypes decreased and a return to one parental species was observed. From an evolutionary point of view, it could be expected that, because we were using morinda as the unique resource, genotypes of $D$ sechellia would be favored, sensitive $D$ simulans genes would be eliminated and a return to pure $D$ sechellia would be observed. In practice the hybrid population returned progressively to a pure $D$ simulans phenotype. $D$ simulans is known to have a major competitive advantage over $D$ sechellia because of its higher egg production ( $\mathrm{R}^{\prime} \mathrm{Kha}$ et al, 1997). This advantage apparently overcame the probable opposite selective pressure imposed by morinda. It was also supposed that, because hybrid flies were observed for several months, the morinda selection might produce resistant $D$ simulans. This $D$ simulans population was kept in laboratory bottles as a mass culture. After a few generations, its tolerance to octanoic acid was measured and the LD50 was 1.61 (confidence interval: 1.51-1.71), practically identical to that observed in pure $D$ simulans.

The fact that $D$ simulans is extremely sensitive to octanoic acid while $D$ sechellia is about eight times more tolerant offers favorable conditions for artificial selection. Starting from BCsim flies, adults were exposed to octanoic acid, the survivors were used to produce the next generation, which was again selected. Results are given in table III. 
Previous studies (table I) indicated that, for BCsim females, the LD50 was $3.5 \mu \mathrm{L}$. In the first generation, selection was applied to females only. All males were kept since the proportion of fertile individuals in that generation is very low. A dose of $4 \mu \mathrm{L}$ was used and 73 surviving females out of 229 were selected to produce the next generation. The average survival time of the reproductive females was $25.8 \mathrm{~h}$. These females were mated to unselected males of the same generation. In the next generation, females only were again selected, but with a higher concentration of $5 \mu \mathrm{L}$. Only $18 \%$ of the females were kept with a survival time of $21.1 \mathrm{~h}$. At the third generation, both sexes could be selected with the same dose. Less than $20 \%$ of adults were kept and the survival time was close to $20 \mathrm{~h}$. The procedure was repeated in G4 and G5 (see table III) without any indication of a better survival. In G6 the selecting dose was decreased to $4 \mu \mathrm{L}$. Survival time in females was longer than in G1 (36.1 against $25.8 \mathrm{~h}$ ), but the selection pressure was stronger $(23 \%$ surviving versus $32 \%$ ). No significant tendency of an increased tolerance was found. In the G7 generation, the LD50 was precisely measured using several doses. The observed values were 2.08 and $1.77 \mu \mathrm{L}$ for females and males respectively. These values are much lower than those observed in the first backcross generation and close to the values found in pure $D$ simulans. In spite of the strong directional selection applied for several successive generations, the average tolerance to octanoic acid did not increase but significantly decreased, regressing to the low values typical of $D$ simulans.

Table III. Results of a selection experiment with octanoic acid, aimed at introgressing the tolerance of $D$ sechellia into the genome of $D$ simulans.

\begin{tabular}{lcccccc}
\hline Generation & $\begin{array}{c}\text { Selected } \\
\text { sex }\end{array}$ & $\mathrm{N}$ & $\begin{array}{c}\text { Surviving } \\
\text { flies }\end{array}$ & $\begin{array}{c}\text { Selection } \\
\text { pressure }\end{array}$ & $\begin{array}{c}\text { Time }( \pm \text { se }) \\
(\mathrm{h})\end{array}$ & $\begin{array}{c}\text { Dose of } \\
\text { C8 }(\mu \mathrm{L})\end{array}$ \\
\hline $\mathrm{G} 1$ & $\mathrm{~F}$ & 229 & 73 & $32 \%$ & $25.75 \pm 2.05$ & 4 \\
$\mathrm{G} 2$ & $\mathrm{~F}$ & 287 & 52 & $18 \%$ & $21.11 \pm 1.66$ & 5 \\
$\mathrm{G} 3$ & $\mathrm{~F}$ & 299 & 51 & $17 \%$ & $18.16 \pm 1.55$ & 5 \\
& $\mathrm{M}$ & 293 & 60 & $20 \%$ & $21.33 \pm 1.45$ & 5 \\
$\mathrm{G} 4$ & $\mathrm{~F}$ & 138 & 31 & $22 \%$ & $16.1 \pm 1.50$ & 5 \\
& $\mathrm{M}$ & 149 & 16 & $11 \%$ & $17.24 \pm 1.41$ & 5 \\
$\mathrm{G} 5$ & $\mathrm{~F}$ & 149 & 27 & $18 \%$ & $19.89 \pm 2.03$ & 5 \\
& $\mathrm{M}$ & 150 & 16 & $11 \%$ & $20.93 \pm 0.80$ & 5 \\
$\mathrm{G} 6$ & $\mathrm{~F}$ & 145 & 34 & $23 \%$ & $36.12 \pm 2.40$ & 4 \\
& $\mathrm{M}$ & 148 & 41 & $28 \%$ & $41.86 \pm 3.58$ & 4 \\
\hline
\end{tabular}

First G1 generation corresponds to the backcross generation ie, the progeny of hybrid females and $D$ simulans males. F: females; M: males; N: number of treated flies; Time: average treatment duration of surviving selected flies; $( \pm \mathrm{se})$ : standard error.

\section{DISCUSSION AND CONCLUSION}

Contrary to previous observations (Farine et al, 1996), we found that hexanoic acid exhibited a strong toxicity similar to that observed for octanoic acid. Both acids 
appear to be involved in the high toxicity of the morinda for all Drosophila species tested so far, except $D$ sechellia. The discrepancy between our data and those of Farine et al (1996) is probably due to technical differences: we counted dead flies after 2 days of treatment instead of less than $1 \mathrm{~h}$, and we used large plastic vials instead of small Petri dishes.

On average, hexanoic acid appeared slightly less toxic than octanoic acid, although the physiological basis of that difference is not known. It might be due to differences in water solubility or in vapor pressure, or in the sensitivity of the biological target. Interestingly the difference varied according to genotype and species. C8 is three times more toxic than C6 for $D$ simulans, while the difference is almost nil in $D$ sechellia. Hybrid genotypes in this respect are more similar to the $D$ sechellia parent.

For each acid, tolerance varies mainly in an additive way (fig 2), F1 individuals are close to the mid-parent value and backcrosses are intermediate between F1 and parent. This conclusion contrasts with previous results obtained with natural morinda (R'Kha et al, 1991), which showed an almost complete dominance of the high tolerance found in $D$ sechellia. This discrepancy does not reflect different genetic mechanisms but, more probably again, a technical difference. With morinda it was difficult to manipulate the quantity of toxin and, in fact, a large amount was used. This quantity was insufficient to kill $D$ sechellia or F1 hybrids. A similar observation may be drawn from figure 1. A dose of $6 \mu \mathrm{L}$ is sufficient to kill almost $100 \%$ of $D$ simulans while in $D$ sechellia and F1, mortality remains below $20 \%$.

Results illustrated in figure 2 suggest an additive inheritance but do not allow precise inference on the number of loci involved in morinda tolerance, and for that goal, specific markers should be used. We tried to check the possible occurrence of tolerance genes on the X-chromosome but the results are difficult to interpret. Because of the direction of the parental cross (female $D$ simulans with male $D$ sechellia) any tolerance carried by the X-chromosome should be expressed in F1 females but not in males. A significant difference was indeed observed between sexes in the F1, females being more tolerant than males. However, the difference almost disappeared in the backcross generations. Moreover, a general tendency seems to exist for females to be more tolerant than males, and the small sex by genotype interaction is difficult to explain by specific genes on the $\mathrm{X}$-chromosome. We may conclude that, even if small effects of the X-chromosome are possible, the major difference between the two species is autosomal.

Among backcross progeny, a small percentage of males are fertile (Lachaise et al, 1986) and it is thus possible to breed successive generations without further backcrosses. With this procedure, male fertility is selected for and progressively restored to a value approaching $100 \%$. This phenomenon, which was analyzed in $D$ simulans $\times D$ mauritiana hybrids (David et al, 1976) also occurs between $D$ simulans and $D$ sechellia (unpublished observations). Interestingly the morphological traits also change and progressively return to the phenotype characteristic of the pure species. More precisely, if the backcross of the F1 females is made with $D$ simulans males, the population will progressively return to a pure $D$ simulans phenotype, while a backcross with $D$ sechellia will lead to a return to $D$ sechellia. Such a progressive evolution is easy to observe by studying male genitalia, which are very different between the three species of the $D$ simulans complex (Tsacas and Bächli, 1981; 
Lemeunier et al, 1986). In the backcross generation, a broad variability is observed (Coyne and Kreitman, 1986; Lemeunier et al, 1986) with numerous intermediate phenotypes. These intermediate, ie, introgressed, genotypes progressively disappear over generations, and this was observed in our population room in which a hybrid swarm was progressively replaced by a pure $D$ simulans. Interestingly, the tolerance to aliphatic acids returned to the low level typical of $D$ simulans, in spite of the probable selection imposed by natural morinda.

In the case of the three Drosophila species belonging to the $D$ simulans complex (including $D$ mauritiana and $D$ sechellia), the introgression of single visible recessive markers is generally possible without special trouble (personal observations). We hoped that, if the tolerance to aliphatic acids in $D$ sechellia was due to a single major gene, responsible for the higher tolerance in F1 flies, this allele could be introgressed into $D$ simulans by our selection procedure. This was obviously not the case, suggesting that, again, the tolerance in $D$ sechellia has a polygenic basis. Two kinds of hypotheses may be considered for explaining the failure to introgress this polygenic trait. A first explanation is a stochastic loss related to a small population size and also to the small number of chromosomes in Drosophila (Hospital et al, 1992). A second interpretation is that several alleles of minor effects, dispersed over the genome, were actively counter selected, for example if they were linked to sterility genes. In Drosophila, male sterility genes, revealed in interspecific crosses are known to be widespread over the genome (Coyne et al, 1991; Cabot et al, 1994; Davis and $\mathrm{Wu}, 1996)$. Data, similar to our observation, ie, difficulty or impossibility to introgress as heterospecific genome, have been recently described in Helianthus (Rieseberg et al, 1995a, b, 1996) and in Anopheles (Della Torre et al, 1997). The barrier to introgression, which may be observed in laboratory experiments, reminds us of hybrid zones observed among natural populations of various species (Barton and Hewitt, 1985; Hewitt, 1989).

The number of loci that are modified during the speciation process remains a subject of debate (Coyne, 1992). In the case of $D$ sechellia adapting to morinda, it seemed a priori more probable that, during a relatively short evolutionary time, a single gene underwent a major mutation responsible for the tolerance. Our data strongly contradict this idea and favor the occurrence of several genes. However, a difficulty remains. If polygenic systems were selected in $D$ sechellia, why was that impossible in $D$ simulans; and also why, up to now, is $D$ sechellia the only species tolerating hexanoic and octanoic acid?

\section{ACKNOWLEDGMENTS}

We thank S R'Kha for her participation in the population room experiment, JC Moreteau for providing the statistical program used for calculating LD50, and F Hospital for drawing our attention to the Helianthus introgression experiments.

\section{REFERENCES}

Bächli L, Rocha-Pité MT (1981) Drosophilidae of the paleartic region. In: The Genetics and Biology of Drosophila, Vol 3a (M Ashburner, HL Carson, JN Thompson, eds), Academic Press, New York, 168-196 
Barton NH, Hewitt GM (1985) Analysis of hybrid zones. Annu Rev Ecol System 16, 113148

Cabot EL, Davis AW, Johnson NA, Wu CI (1994) Genetics of reproduction in the Drosophila simulans clade: complex epistasis underlying hybrid male sterility. Genetics 137, 175-189

Chakir M, Peridy O, Capy P, Pla E, David JR (1993) Adaptation to alcoholic fermentation in Drosophila: a parallel selection imposed by environmental ethanol and acetic acid. Proc Natl Acad Sci USA 90, 3621-3625

Connell JH (1980) Diversity and the coevolution of competitors or the ghost of competition past. Oikos $35,131-138$

Coyne JA, Kreitman M (1986) Evolutionary genetics of two sibling species, Drosophila simulans and $D$ sechellia. Evolution 40,673-691

Coyne JA, Rux J, David JR (1991) Genetics of morphological differences and hybrid sterility between Drosophila sechellia and its relatives. Genet Res Camb 57, 113-122

Coyne JA (1992) Genetics and speciation. Nature 355, 511-515

David JR, Clavel MF (1965) Interaction entre le génotype et le milieu d'élevage. Conséquences sur les caractéristiques du développement de la drosophile. Bull Biol Fr Belg 99, 369-378

David JR, Bocquet C, Lemeunier F, Tsacas L (1976) Persistance of male sterility in strains issued from hybrids between two sibling species: Drosophila simulans and $D$ mauritiana. J Genet 62, 63-100

David JR, Merçot H, Capy P, McEvey SF, Van Herrewege J (1986) Alcohol tolerance and Adh gene frequencies in European and African populations of Drosophila melanogaster. Genet Sel Evol 18, 405-416

Davis AW, Wu CI (1996) The broom of the sorcerer's apprentice: the fine structure of a chromosomal region causing reproductive isolation between two sibling species of Drosophila. Genetics 143, 1287-1298

Della Torre A, Merzagora L, Powell JR, Coluzzi M (1997) Selective introgression of paracentric inversions between two sibling species of the Anopheles gambiae complex. Genetics 146, 239-244

Farine JP, Legal L, Moreteau B, Le Quere JL (1996) Volatile components of ripe fruits of Morinda citrifolia and their effect on Drosophila. Phytochemistry 41, 433-438

Feder JL, Chicote CA, Bush GL (1990a) The geographic differentiation between host associated populations of Rhagoletis pomonella (Diptera, Tephritidae) in the eastern United States and Canada. Evolution 44, 570-594

Feder JL, Chicote CA, Bush GL (1990b) Regional, local and microgeographical allele frequency variation between apple and hawthorn populations of Rhagoletis pomonella in western Michigan. Evolution 44, 595-608

Harborne JB (1989) Introduction to Ecological Biochemistry. Academic Press, London

Hewitt GM (1989) The subdivision of species by hybrid zones. In: Speciation and its Consequences (D Otte, JA Endler, eds), Sinauer, Sunderland, 85-110

Higa I, Fuyama Y (1993) Genetics of food preference in Drosophila sechellia. I. Response to food attractants. Genetica $88,129-136$

Hospital F, Chevalet C, Mulsant P (1992) Using markers in gene introgression breeding programs. Genetics 132, 1199-1210

Hutchinson GE (1978) An Introduction to Population Ecology. Yale University Press, New Haven

Lachaise D, David JR, Lemeunier F, Tsacas L, Ashburner M (1986) The reproduction relationships of Drosophila sechellia with $D$ mauritiana, $D$ simulans, $D$ melanogaster from the Afrotropical region. Evolution 40, 262-271 
Legal L, David JR, Jallon JM (1992) Toxicity and attraction effects produced by Morinda citrifolia on the Drosophila melanogaster complex of species. Chemoecology, 125-129

Legal L, Chappe B, Jallon JM (1994) Molecular basis of Morinda citrifolia (L.): toxicity on Drosophila. J Chem Ecol 20, 1931-1943

Lemeunier F, David JR, Tsacas L, Ashburner M (1986) The melanogaster species group. In: The Genetics and Biology of Drosophila, Vol 3e (M Ashburner, HL Carson, JN Thompson, eds), Academic Press London, 147-256

Louis J, David JR (1986) Ecological specialization in the Drosophila melanogaster species subgroup: a case study of $D$ sechellia. Acta Ecologica, Ecol Gener 7, 215-219

Pianka E (1974) Evolutionary Ecology. Harper and Row, New York

Pielou EC (1975) Ecological Diversity. Wiley and Sons, New York

Price PW (1984) Insect Ecology. John Wiley, New York

R'Kha S, Capy P, David JR (1991) Host-plant specilization in the Drosophila melanogaster species complex: a physiological, behavioral, genetical analysis. Proc Natl Acad Sci USA 88, 1835-1839

R'Kha S, Moreteau B, Coyne JA, David JR (1997) Evolution of a lesser fitness trait: egg production in the specialist Drosophila sechellia. Genet Res Camb 69, 17-23

Rieseberg LH, Randal Linder C, Seiler GJ (1995a) Chromosomal and genic barriers to introgression in Helianthus. Genetics 141, 1163-1171

Rieseberg LH, Fossen CV, Desrochers AM (1995b) Hybrid speciation accompanied by genomic reorganization in wild sunflowers. Nature 375, 313-316

Rieseberg LH, Sinervo B, Linder CR Ungerer MC, Arias DM (1996) Role of gene interaction in hybrid speciation: evidence from ancient and experimental hybrids. Science 272, 741-744

Thompson JN, Wehling W, Podolsky R (1990) Evolutionary genetic of host use in swallowtail butterflies. Nature $344,148-150$

Tilman D (1982) Resource Competition and Community Structure. Princeton University Press, Princeton

Tsacas L, Bächli G (1981) Drosophila sechellia, n sp, huitième espèce du sous groupe melanogaster des îles Seychelles (Diptera, Drosophilidae). Rev Fr Entomol (NS) 3, $146-150$

Tsacas L, Lachaise D, David JR (1981) Composition and biogeography of Drosophilid fauna. In: The Genetics and Biology of Drosophila, Vol 3a (M Ashburner, HL Carson, JN Thompson, eds), Academic Press London, 197-259 